\title{
Fostering cognitive-emotional processing in the treatment of depression: a preliminary investigation in exposure-based cognitive therapy
}

Grosse Holtforth, Martin ; Hayes, Adele M ; Sutter, Marielle ; Wilm, Katharina ; Schmied, Emma ; Laurenceau, Jean-Philippe ; Caspar, Franz

DOI: https://doi.org/10.1159/000336813

Posted at the Zurich Open Repository and Archive, University of Zurich ZORA URL: https://doi.org/10.5167/uzh-66409

Journal Article

Published Version

Originally published at:

Grosse Holtforth, Martin; Hayes, Adele M; Sutter, Marielle; Wilm, Katharina; Schmied, Emma; Laurenceau, Jean-Philippe; Caspar, Franz (2012). Fostering cognitive-emotional processing in the treatment of depression: a preliminary investigation in exposure-based cognitive therapy. Psychotherapy and Psychosomatics, 81(4):259-260.

DOI: https://doi.org/10.1159/000336813 
Psychother Psychosom 2012;81:259-260

DOI: $\underline{10.1159 / 000336813}$

\section{Fostering Cognitive-Emotional Processing in the Treatment of Depression: A Preliminary Investigation in Exposure-Based Cognitive Therapy}

\author{
Martin Grosse Holtforth ${ }^{\mathrm{a}}$, Adele M. Hayes ${ }^{\mathrm{c}}$, Marielle Sutter ${ }^{\mathrm{a}}$, \\ Katharina Wilm ${ }^{\mathrm{a}}$,Emma Schmied ${ }^{\mathrm{b}}$, Jean-Philippe Laurenceau', \\ Franz Caspar ${ }^{\mathrm{b}}$ \\ a University of Zurich, Zurich, and b University of Bern, Bern, \\ Switzerland; ' University of Delaware, Newark, Del., USA
}

Processing is hypothesized to be a central mechanism of change across psychotherapies, and exposure-based and other affectively charged interventions are potent ways to facilitate this [1-3]. Processing involves changing maladaptive associations between stimuli, responses, and meaning by activating this network of associations, introducing inconsistent information, and facilitating new responses $[4,5]$. Emotional arousal plus cognitive reflection, rather than arousal alone, is associated with lasting changes [6], and cognitive-emotional processing of adverse experiences provides more benefit than avoidance [7]. Whereas exposure-based interventions are considered highly effective in anxiety therapy, the application of exposure principles to depression is in its infancy $[8,9]$.

Exposure-based cognitive therapy (EBCT) $[8,9]$ applies principles of exposure and processing $[10,11]$ to the treatment of depression. In this study, EBCT is a 20 -session treatment that facilitates processing by helping patients to: (a) decrease avoidance and rumination (phase 1; 5-6 sessions), (b) approach avoided emotions and explore and disrupt depressive patterns (phase 2; 8-10 sessions), and (c) develop and strengthen more adaptive patterns (phase $3 ; 5-6$ sessions) $[5,12,13]$. In phase 2 , therapists use techniques akin to imaginal exposure, and patients gradually confront and explore experiences related to their negative views of self. Emotion-focused interventions, such as the two-chair and empty-chair dialogue [3], help patients process these experiences more deeply $[8,9]$.

In the first open trial of EBCT [8] with 29 depressed patients, symptoms reduced significantly after 24 sessions $(\mathrm{d}=2.32)$. Growth curve analyses revealed a cubic trajectory of change (initial symptom decrease, increase during exposure, decrease again). Peak levels of arousal and processing occurred during exposure, which then predicted outcome.

The current study assessed the generalizability of EBCT in a sample of depressed Swiss outpatients. We hypothesized (a) a decrease in depressive symptoms and avoidance, (b) a cubic shape of change, (c) highest levels of arousal and processing in phase 2, and (d) that processing in phase 2 would predict outcome.

After informed consent all patients were administered structured clinical interviews (SKID-I) [14]. Patients were eligible if they met criteria for a primary diagnosis of major depressive episode, were 18-65 years of age, did not meet criteria for the following disorders: psychotic, bipolar, post-traumatic stress, obsessivecompulsive, borderline personality, or substance dependence, and did not report acute suicidality. Previously stable antidepressant medication was permitted.

Twenty-four patients were included, and 21 patients completed the study. Reasons for dropout were unrelated to the treatment. Demographic data were as follows: 23 were Caucasian, 14 were females, mean age was 33 (20-52 years, $S D=9.7), 16$ were singles, and 13 had at least a 12th grade education. This was the first episode of depression for 5 patients; 8 had at least one comorbid disorder. Personality disorders were not routinely assessed. Sixteen patients did not take psychiatric medication. Nine of 13 therapists were women, all were Caucasian, and their mean age was 36 (30-47 years). Therapists were experienced staff members $(n=5)$ or advanced masterslevel therapists in postgraduate psychotherapy training $(n=8)$. All therapists had had previous postgraduate courses on cognitive-behavioral, process-experiential and resource-focused interventions [15]. In addition, therapists had had a full workshop on EBCT and met biweekly for supervision over the trial.

Depression symptoms were assessed on admission and after 20 sessions using the German Beck Depression Inventory (BDI-II), which has satisfactory internal consistency, test-retest reliability, convergent and discriminant validity, and sensitivity to change [16]. Before each session, patients completed the 5-item WHO Well-Being Index, which is also a highly sensitive and specific measure of clinical depression with high internal consistency, validity and sensitivity to change [17]. The German Cognitive-Behavioral Avoidance Scale assessed avoidant behaviors and has shown good factor structure, internal consistency, and test-retest reliabilities $[18,19]$. After every session, the Bern Post-Session Report was rated by both patient and therapist to assess affective engagement (e.g. 'I was very emotionally involved in today's session'/'Today I worked towards getting the patient emotionally involved') and cognitive-emotional processing (e.g. 'I have the feeling that I got a better understanding of myself and my problems today'/'Today I actively tried to help the patient see his/her problems in a new light'). The scales of the Bern Post-Session Report have a sound factorial structure and internal consistencies [20].

Pre- to posttreatment changes in symptoms of depression and avoidance were examined by conducting MANOVAs on BDI-II scores and avoidance for the intent-to-treat $(\mathrm{n}=24)$ and completer samples $(n=21)$. Both scores decreased significantly (table 1$)$, and effect sizes are similar to those of the original EBCT trial [1] and to benchmark effects [21]. Sixteen patients (76\%) demonstrated clinically significant change (pre-post difference minimum 8 points, BDI-II post $\left._{\text {p }}<20\right)[16], 15(71 \%)$ were treatment responders (BDI-II <20), and $12(57.1 \%)$ remitted (BDI-II <10). Hierarchical linear modeling, using orthonormalized polynomial coefficients as time-based predictors [22], yielded significant linear and cubic patterns of change [intercept: $\beta_{00}=12.97, \mathrm{SE}=0.94, \mathrm{t}(19)=13.86$,

\section{KARGER}

Fax +4161306 1234 E-Mail karger@karger.ch www.karger.com
C 2012 S. Karger AG, Basel

$0033-3190 / 12 / 0814-0259 \$ 38.00 / 0$

Accessible online at: www.karger.com/pps
Prof. Dr. Martin Grosse Holtforth

University of Zurich, Department of Psychology

Binzmühlestrasse 14/19

CH-8050 Zurich (Switzerland)

Tel. +41 44635 7300, E-Mail grosse@ psychologie.uzh.ch 
Table 1. Pretreatment to posttreatment changes in depression and avoidance behavior

\begin{tabular}{|c|c|c|c|c|c|c|}
\hline & & & $\begin{array}{l}\text { Pretreatment } \\
(\text { mean } \pm S D)\end{array}$ & $\begin{array}{l}\text { Posttreatment } \\
(\text { mean } \pm S D)\end{array}$ & $\begin{array}{l}\text { Pre-to-post } \\
\text { difference } \\
\mathrm{F}(1,23) / \mathrm{F}(1,20)\end{array}$ & $\begin{array}{l}\text { Effect size } \\
\text { Cohen's d } \\
\left(\mathrm{SD}_{\text {pooled }}\right)\end{array}$ \\
\hline Avoidance behavior & CBAS/KBVS & $\begin{array}{l}\text { intent-to-treat }(\mathrm{n}=24) \\
\text { completers }(\mathrm{n}=21)\end{array}$ & $\begin{array}{l}2.46 \pm 0.58 \\
2.53 \pm 0.57\end{array}$ & $\begin{array}{l}2.09 \pm 0.55 \\
2.10 \pm 0.56\end{array}$ & $\begin{array}{l}11.79^{*} \\
12.64^{*}\end{array}$ & $\begin{array}{l}0.65 \\
0.74\end{array}$ \\
\hline
\end{tabular}

Results of post hoc univariate tests from MANOVA (significant omnibus F, p < 0.05). CBAS = Cognitive-Behavioral Avoidance Scale (KBVS $=$ German version). MANOVAs were conducted to compare pretreatment to posttreatment differences for each variable. ${ }^{*} \mathrm{p}<0.01 ;{ }^{* *} \mathrm{p}<0.001$.

$\mathrm{p}<0.001$; linear: $\beta_{10}=5.84, \mathrm{SE}=1.52, \mathrm{t}(19)=3.84, \mathrm{p}<0.001$; quadratic: $\beta_{20}=-0.97, \mathrm{SE}=1.37, \mathrm{t}(19)=-0.71$, n.s.; cubic: $\beta_{30}=2.19$, $\mathrm{SE}=1.01, \mathrm{t}(19)=2.17, \mathrm{p}<0.05]$. Average affective engagement and processing ratings for both patient and therapist were higher in phase 2 than in phase 1 [affective engagement: $F(1,20)=24.96$, $\mathrm{p}<0.001, \mathrm{~d}=1.01$ (patient); $\mathrm{F}(1,20)=56.74, \mathrm{p}<0.001, \mathrm{~d}=2.41$ (therapist); processing: $\mathrm{F}(1,20)=16.26, \mathrm{p}<0.01, \mathrm{~d}=0.61$ (patient); $\mathrm{F}(1,20)=33.05, \mathrm{p}<0.001, \mathrm{~d}=1.69$ (therapist)]. Controlling for admission levels of depression, processing in phase 2 predicted change in BDI-II (partial $\mathrm{r}=-0.45, \mathrm{p}<0.05$ ), whereas processing in phase 1 did not (partial $r=0.01$, n.s.). Findings are consistent with each of our hypotheses.

Limitations include the small sample size, lack of ethnic diversity, naturalistic design, no control condition, self-reported symptom assessment, no follow-up, diagnoses only on admission, no SKID reliability, no assessment of personality disorders, and adherence/treatment integrity ratings only by therapists.

We present initial evidence for the generalizability of EBCT to a different language and culture and using different assessment methods. A cubic change pattern seems to be an important characteristic of emotionally challenging therapies [23], and cognitive-emotional processing was again an important predictor of change in the treatment of depression $[8,9]$, as it is in anxiety disorders. In an ongoing randomized-controlled trial comparing EBCT with cognitive-behavioral therapy, we will examine the efficacy of EBCT, long-term outcomes, as well as potential differential change processes.

\section{References}

1 Brewin CR, Dalgleish T, Joseph S: A dual representation theory of posttraumatic stress disorder. Psychol Rev 1996;103:670-686.

2 Foa EB, Kozak MJ: Emotional processing of fear: exposure to corrective information. Psychol Bull 1986;99:20-35.

3 Greenberg LS, Watson JC: Emotion-Focused Therapy for Depression. Washington, American Psychological Association, 2006.

4 Lang PJ: Imagery in therapy: an information processing analysis of fear. Behav Ther 1977;8:862-886.

5 Carey TA: Exposure and reorganization: the what and how of effective psychotherapy. Clin Psychol Rev 2010;31:236-248.

6 Whelton WJ: Emotional processes in psychotherapy: evidence across therapeutic modalities. Clin Psychol Psychother 2004;11:58-71.

7 Grosse Holtforth M: Avoidance motivation in psychological problems and psychotherapy. Psychother Res 2008;18:147-159.
8 Hayes AM, Beevers CG, Feldman GC, Laurenceau J-P, Perlman C: Avoidance and processing as predictors of symptom change and positive growth in an integrative therapy for depression. Int J Behav Med 2005; $12: 111-122$

9 Hayes AM, Feldman GC, Beevers CG, Laurenceau J-P, Cardaciotto LA, Lewis-Smith J: Discontinuities and cognitive changes in an exposurebased cognitive therapy for depression. J Consult Clin Psychol 2007;75: 409-421.

10 Foa EB, Huppert JD, Cahill SP: Emotional processing theory: an update; in Olasov Rothbaum B (ed): Pathological Anxiety: Emotional Processing in Etiology and Treatment. New York, Guilford, 2006, pp 3-24.

11 Teasdale JD: Emotional processing, three modes of mind and the prevention of relapse in depression. Behav Res Ther 1999;37:53-77.

12 Trew JL: Exploring the roles of approach and avoidance in depression: an integrative model. Clin Psychol Rev 2011;31:1156-1168.

13 Fava GA: Well-being therapy: conceptual and technical issues. Psychother Psychosom 2000;68:171-179.

14 Wittchen H, Wunderlich U, Gruschwitz S, Zaudig M: SKID-I. Strukturiertes Klinisches Interview für DSM-IV. Göttingen, Hogrefe, 1997.

15 Flückiger C, Caspar F, Grosse Holtforth M, Willutzki, U: Working with patients' strengths: a microprocess approach. Psychother Res 2009;1: 213-223.

16 Kühner C, Bürger C, Keller F, Hautzinger M: Reliabilität und Validität des revidierten Beck-Depressionsinventars (BDI-II). Der Nervenarzt 2007;78:651-656.

17 Newnham EA, Hooke GR, Page AC: Monitoring treatment response and outcomes using the World Health Organization's Wellbeing Index in psychiatric care. J Affect Dis 2010;122:133-138.

18 Ottenbreit ND, Dobson KS: Avoidance and depression: the construction of the cognitive-behavioral avoidance scale. Behav Res Ther 2004; 42:293-313.

19 Röthlin P, Grosse Holtforth M, Bergomi C, Berking M, Ottenbreit ND, Caspar F: Vermeidung und Depression. Diagnostica 2010;56:46-55.

20 Flückiger C, Regli D, Zwahlen D, Hostettler S, Caspar F: Der Berner Patienten- und Therapeutenstundenbogen 2000. Z Klin Psychol Psychiatr Psychother 2010;39:71-79.

21 Minami T, Wampold BE, Serlin RC, Kircher JC, Brown GSJ: Benchmarks for psychotherapy efficacy in adult major depression. J Consult Clin Psychol 2007;75:232-243.

22 Hedeker D: An introduction to growth modeling; in Kaplan D (ed): The Sage Handbook of Quantitative Methodology for the Social Sciences. Thousand Oaks, Sage Publications, 2004, pp 215-234.

23 Brakemeier E-L, Engel V, Schramm E, Zobel I, Schmidt T, Hautzinger M, Berger M, Normann C: Feasibility and outcome of Cognitive Behavioral Analysis System of Psychotherapy (CBASP) for chronically depressed inpatients: a pilot study. Psychother Psychosom 2011;80:191194. 